\title{
IFA and PIFA Size Reduction by Using a Stub Loading
}

\author{
Jose Alfredo Tirado-Mendez, ${ }^{1}$ Rene Acevo-Herrera, ${ }^{2}$ Ruben Flores-Leal, ${ }^{3}$ \\ Roberto Linares-Miranda, ${ }^{1}$ and Hildeberto Jardon-Aguilar ${ }^{3}$ \\ ${ }^{1}$ Instituto Politecnico Nacional, SEPI-ESIME Zacatenco, U. P. Adolfo Lopez Mateos, 07738 Mexico City, DF, Mexico \\ ${ }^{2}$ Universitat Politecnica de Catalunya, Department of Signal Theory \& Communications, Remote Sensing Lab, 08034 Barcelona, Spain \\ ${ }^{3}$ CINVESTAV-IPN, Telecommunications Section, San Pedro Zacatenco, 07360 Mexico City, DF, Mexico
}

Correspondence should be addressed to Tirado-Mendez Jose Alfredo; jtiradom@ipn.mx

Received 5 June 2013; Revised 22 August 2013; Accepted 10 October 2013

Academic Editor: Z. N. Chen

Copyright (C) 2013 Tirado-Mendez Jose Alfredo et al. This is an open access article distributed under the Creative Commons Attribution License, which permits unrestricted use, distribution, and reproduction in any medium, provided the original work is properly cited.

\begin{abstract}
A proposed technique for size reduction of a conventional inverted-F antenna (IFA) and a planar inverted-F antenna (PIFA) by employing a reactive load generated by a short-circuited stub is presented. The reduction factor of both antennas is around $30 \%$, and the main parameters of the devices are preserved, including a fractional bandwidth of $4 \%$ and a gain of $-2 \mathrm{~dB}$. Both antennas operate around $1.5 \mathrm{GHz}$.
\end{abstract}

\section{Introduction}

In the literature, there are several techniques to reduce the dimensions of conventional antennas. Many of them are applied to different kinds of devices, including strip antennas and wire antennas. Bending, folding, and meandering are techniques for antenna miniaturization, and they have been used since many years ago due to their efficiency [1]. The modification of the structure forces the current to flow along a curved and longer path, resulting in a lower resonant frequency. The inverted-F antenna is evolved from a quarter wavelength antenna, and the following modifications are made to improve the performance of the device [1]. Then, by itself, the IFA and the PIFA antennas are a small version of a resonant monopole. However, as it is demonstrated in this paper, the dimensions of these devices can still be reduced without modifying significantly the main parameters, such as bandwidth, gain, or even cross-polarization levels.

It is well established that reducing its dimensions, the efficiency of the antenna can also be decreased [2]. To get a smaller size, also planar antennas can be folded into multilayered structures, reaching a higher lessening factor leading the antenna to dimensions close to $\lambda / 8$ [3]. In [4] a generalization was proposed for folding the antenna into a multilayered structure. The achieved electric length was close to $\lambda / 8.6$ with a corresponding fractional bandwidth of $2.98 \%$. The PIFA size can also be reduced via capacitive loading of the top plate [5] and by adding a plane between the ground plane and the PIFA [6]. The goal of the capacitive loading is to compensate the inductive portion of the impedance in order to reduce the reactive part of the impedance [5]. Other methods are based on dielectric loading [7] to reduce the PIFA size, by modifying the shorting pin location [8] or by introducing slots [9]. In this paper, a technique based on a stub loading is proposed in order to reduce the dimensions of the IFA and PIFA structures. This method has been successfully applied in different antennas for size reduction, without degrading the main parameters of the device [10-12].

\section{Proposed Technique}

As explained in $[3,4]$, the length of a PIFA can be reduced by folding the radiator; however, the height of the structure is increased. To avoid as much as possible this drawback, the technique proposed in this study allows reducing the length of the radiator without increasing, significantly, the height of the antenna. The proposal for IFA and PIFA size reduction is depicted in Figure 1. 


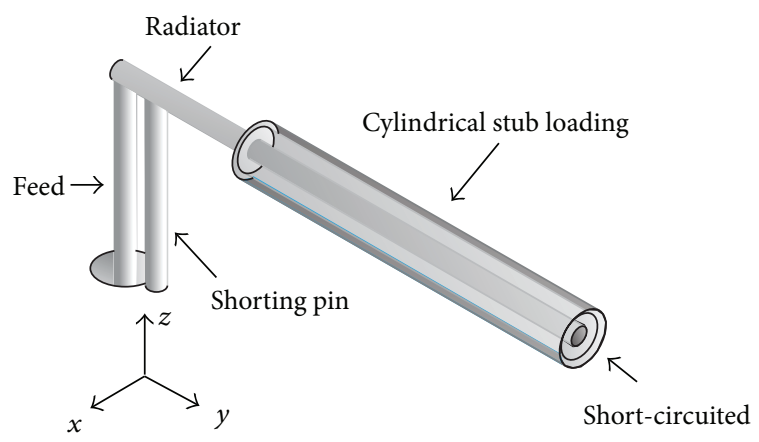

(a)

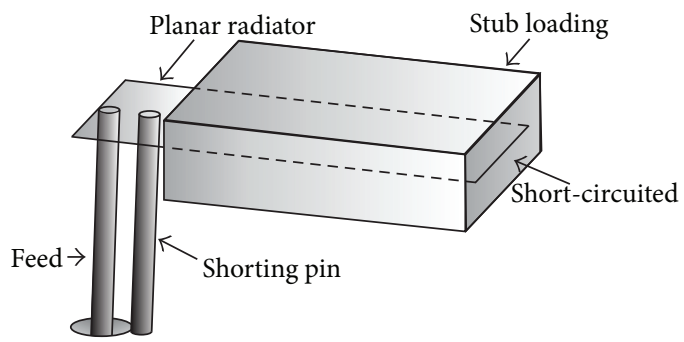

(b)

FIgURE 1: Proposed technique for size reduction. (a) Cylindrical stub loading for IFA and (b) waveguide stub loading for PIFA.

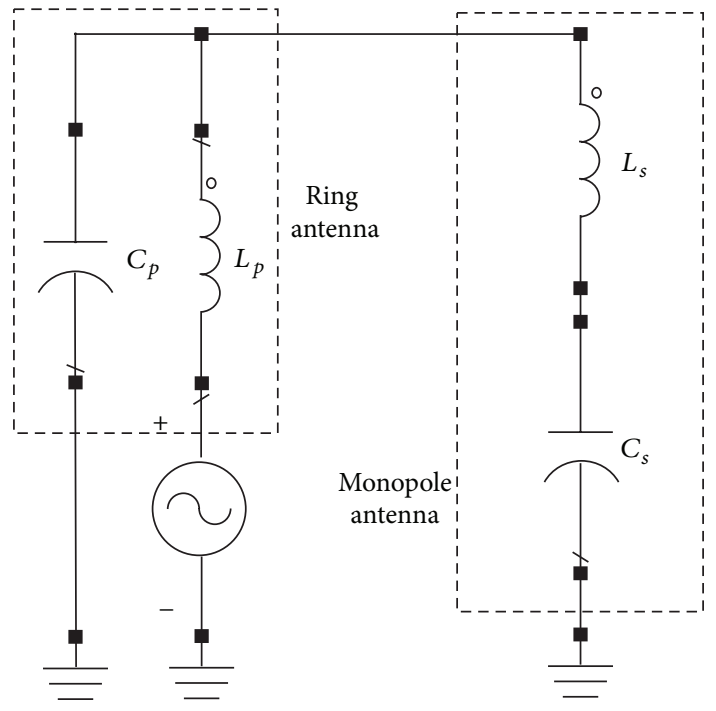

(a)

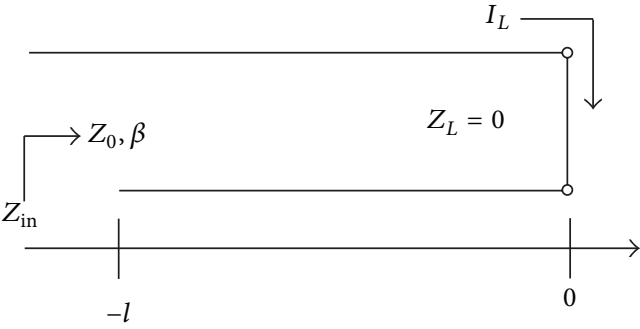

(b)

FIGURE 2: (a) IFA circuit model and (b) stub modeled as a short-circuited lossless transmission line.

Figure 1(a) displays the configuration how the IFA structure is loaded with a cylindrical-shaped stub, which $\mathrm{d}$ the dimensions are depicted in Fi. Figure 1(b) depicts the configuration to reduce the PIFA size. In this case, the stub is implemented by a rectangular waveguide and, as in the case of the IFA configuration, the structure is shortcircuited at the end of the radiator. For both structures, the stub can be filled with a substrate in order to increase the slow-wave factor and longer as a result, making the electric length of the antenna, achieving a higher size reduction.

From Figure 1, it is clear that both antennas can be modeled as an array which is formed by a ring antenna (feeding line and shorting pin) and a monopole antenna (bent radiator). The electric model is displayed in Figure 2(a). According to this model, the main resonance of the antenna is given by the combination of the total inductance and capacitance of the ring and the monopole antennas, $L p$ and $L s$ and $C p$ and $C s$, respectively. The idea of adding a stud load to the monopole is to increase the inductance $L s$, and as a result, the resonance of the antenna is obtained at lower frequencies without modifying the monopole length.

On the other hand, the stub can be modeled as a short-circuited lossless transmission line as observed in Figure 2(b). The behavior of the stub is inductive, and the input impedance is given by

$$
Z_{\text {in }}=j Z_{0} \tan \beta l,
$$

where $Z_{\text {in }}$ is the input impedance, $Z_{0}$ is the transmission line impedance, $\beta$ is the propagation constant, and $l$ is the stub length. As described in (1), the input impedance behaves as an inductive reactance, and this is preserved as long as the stub length, $l$, is less than $\lambda / 4$, which is clearly achieved when it is applied into the IFA or PIFA structure. To demonstrate this behavior, a stub-loaded monopole is simulated and the input impedance response is obtained for different stub lengths. The stub-loaded monopole and its current distribution are depicted in Figure 3(a), and the response is presented in Figure 3(b). 


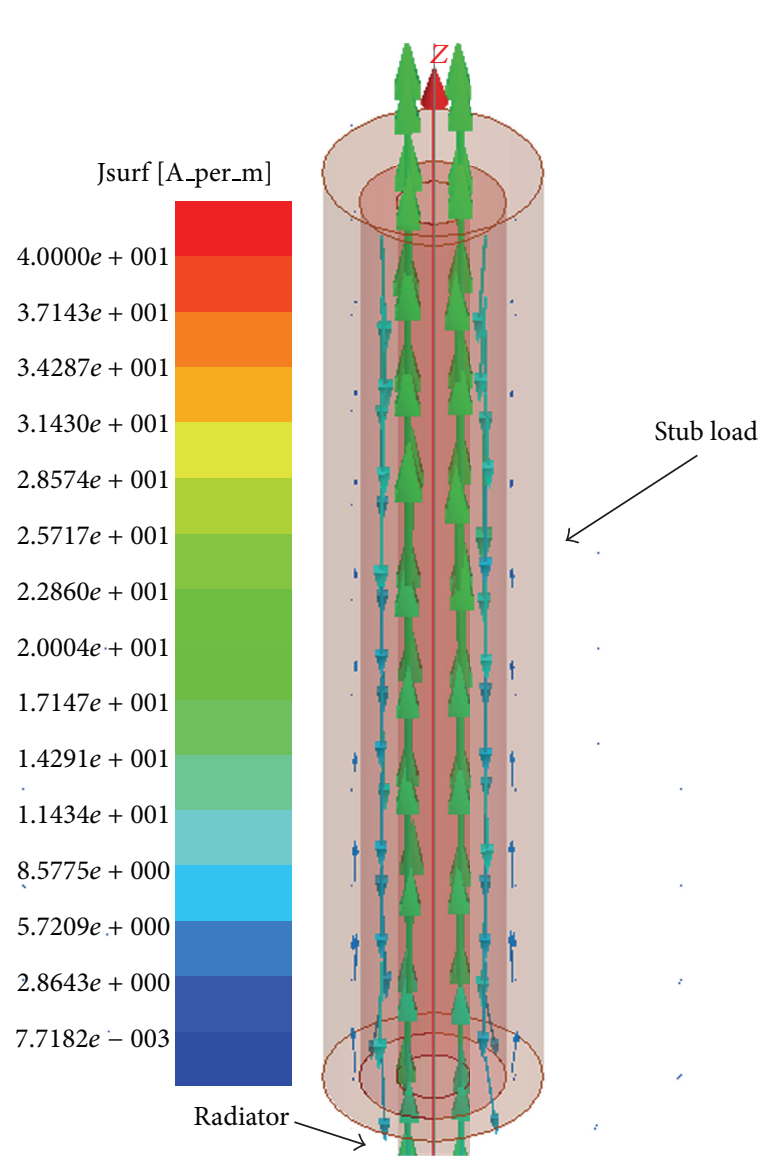

(a)

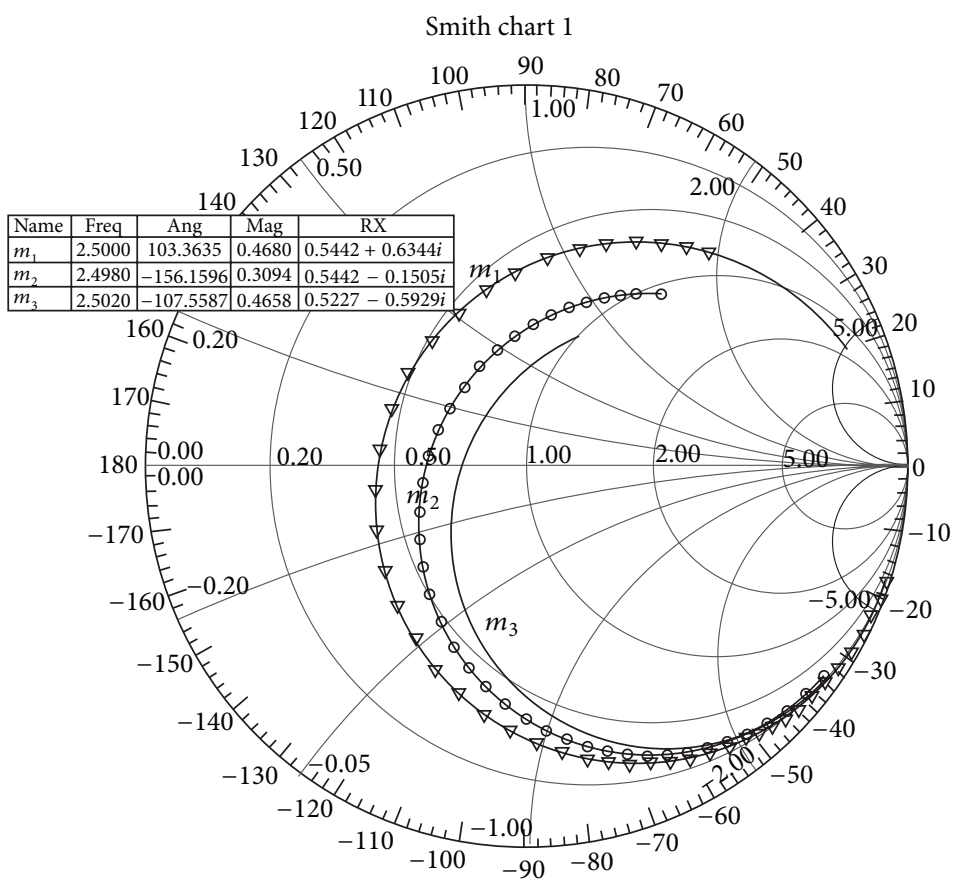

Curve info

$$
\begin{aligned}
- & S(1,1) \\
& \text { long =' } 5 \mathrm{~mm}, \\
- & S(1,1) \\
& \text { long = ' } 10 \mathrm{~mm} ' \\
\rightarrow & S(1,1) \\
& \text { long = ' } 15 \mathrm{~mm} \text { ' }
\end{aligned}
$$

(b)

Figure 3: (a) Current distribution and (b) $S_{11}$ parameter for different stub lengths.

From Figure 3(a) it is seen that the use of the stub load does not present a current flow with a significant magnitude antiparallel to the main trajectory, which leads to no significant reduction of the radiation efficiency. On the other hand, Figure $3(\mathrm{~b})$ shows the $S_{11}$ parameter of the loaded monopole for three different stub lengths: $5 \mathrm{~mm}$, $10 \mathrm{~mm}$, and $15 \mathrm{~mm}$. When the stub length is increased, the imaginary part of the input impedance shows an inductive behavior.

For example, the markers in the figure point out at $2.5 \mathrm{GHz}$, in which the imaginary part of the $S_{11}$ parameter is $-0.59,-0.15$, and 0.63 , corresponding to stub lengths of $5 \mathrm{~mm}, 10 \mathrm{~mm}$, and $15 \mathrm{~mm}$, respectively. As a conclusion, the longer the stub is, the more the inductive load is achieved. On the other hand, from (1) it is clearly noted that the stub performance depends not only on the length but also on the radius.

To demonstrate this behavior, a stub length of $15 \mathrm{~mm}$ is fixed and the radius is varied and so the input impedance, in order to verify the frequency performance of the structure. The results are depicted in Figure 4.

From Figure 4, it is seen that the resonance of the radiator for different stub widths changes when the radius is bigger. However, the bandwidth is also reduced. For example, when

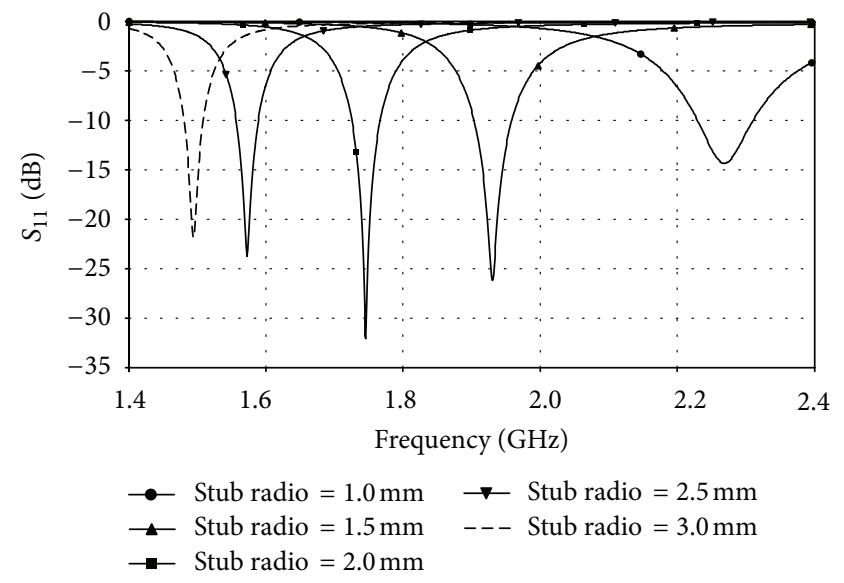

FIGURE 4: $S_{11}$ parameter for a fixed length stub and different radii.

the stub radius is $1 \mathrm{~mm}$, the resonance is around $2.3 \mathrm{GHz}$, and the bandwidth (considering a $S_{11} \leq-10 \mathrm{~dB}$ ) is about $80 \mathrm{MHz}$. On the other hand, when the stub radius is $3.0 \mathrm{~mm}$, the resonance is close to $1.5 \mathrm{GHz}$, but the bandwidth is around $30 \mathrm{MHz}$. 


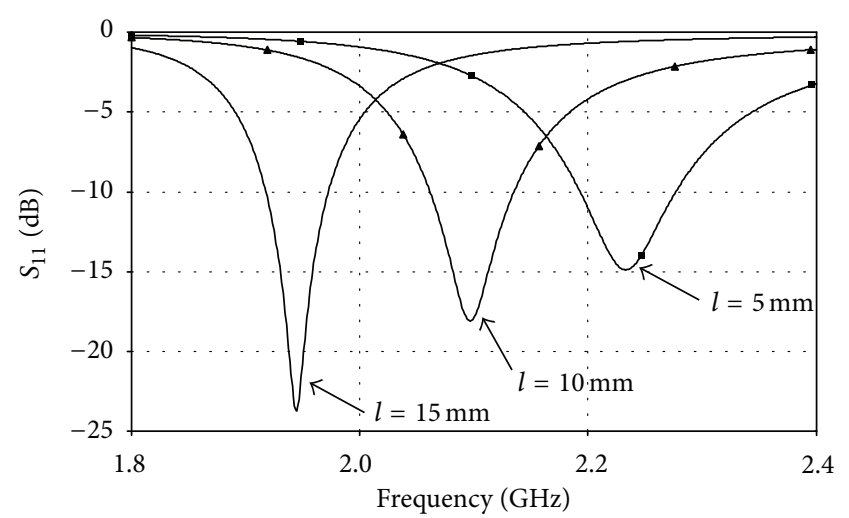

FIGURE 5: $S_{11}$ parameter of the IFA structure for different stub lengths.

From these results, there is a trade-off between the stub radius and the reduction factor which need to be taken into account to be employed in the IFA and PIFA antennas. Considering these facts, a radius of $1.5 \mathrm{~mm}$ is considered, since a good performance is obtained regarding frequency shift, bandwidth, and antenna total volume.

In order to analyze the behavior of the proposed technique into the IFA structures, a design process is made employing a finite element electromagnetic simulation software. A configuration of an IFA as shown in Figure 1(a) with radiator length of $20 \mathrm{~mm}$ is considered, taking into account different stub lengths, $l$. The simulation results are presented in Figure 5. The ground plane for both structures in Figure 1 is $140 \mathrm{~mm} \times 70 \mathrm{~mm}$. The radiator is centered on the ground plane.

As previously demonstrated, the bigger the stub length (the bigger the inductance), the lower the resonant frequency and the better the input port matching, since the real pat of the input impedance is closer to $50 \mathrm{Ohms}$ and the imaginary part is close to zero, as observed in Figure 5. In [5], it is demonstrated by showing the VSWR that while the capacitance load is bigger, not only a smaller resonant frequency is obtained, but also the input matching port is degraded, as well as the bandwidth. Since, in this particular case, the proposed method improves the port matching $\left(S_{11}\right.$ parameter), an advantage compared to the conventional capacitive loading [5] is achieved. On the other hand, a similar frequency behavior is shown by the PIFA with stub. However, in this case, the port matching is almost preserved, as observed in Figure 6, where a loaded PIFA with a radiator length of $25 \mathrm{~mm}$ was studied employing different stub lengths.

For demonstration purposes, an IFA and a PIFA structures were designed, simulated, and characterized, employing the size reduction technique proposed in this work, as seen in the next sections.

\section{Simulated and Measured Results of Proposed Antennas}

In order to demonstrate the efficiency of the proposed method to reduce the dimensions of an IFA and a PIFA, two

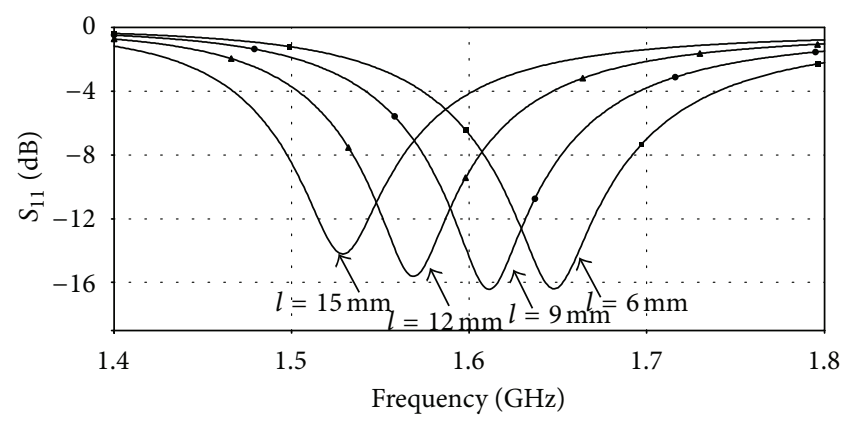

FiguRE 6: $S_{11}$ parameter of the PIFA for different stub lengths.

stub-loaded antennas were designed, simulated, and compared to conventional devices. Both antennas are made to perform around $1.5 \mathrm{GHz}$, and the dimensions are depicted in Figure 7. In both structures, the shorting pin is located at $2 \mathrm{~mm}$ from the feeding line. This dimension is obtained to better the port matching.

The simulation process was made by using an electromagnetic simulation software based on finite element algorithm, and the comparison of the simulated $S_{11}$ parameter of a conventional and the reduced IFA is given in Figure 8. To resonate at the same frequency, the conventional antenna has a radiator length of $43 \mathrm{~mm}$ and the rest of the dimensions are the same as the reduced antenna depicted in Figure 7.

The simulated $S_{11}$ parameter establishes that the loaded antenna shows a slightly less port matching than the conventional one, but the bandwidth is kept. Of course, the resonance can be shifted by barely modifying the stub length, which can also be employed as a tuning technique. On the other hand, Figure 9 presents a comparison of the simulated radiation patterns of both antennas.

As observed in Figure 9, the reduced antenna performs as well as the conventional one, showing both omnidirectionality in the $X-Y$ plane with an average gain of $-1 \mathrm{~dB}$ and a pattern with nulls in the $X-Z$ plane. It is also observed that the reduced antenna seems to have a slightly bigger gain at certain angles. This fact is mainly due since the reduced antenna aperture is somewhat bigger than the conventional one, as a result of the stub volume. Then, using a stub-loaded configuration, the reduced antenna is $30 \%$ shorter than the conventional device, but with a nondegraded performance, since the bandwidth and gain are kept.

On the other hand, the reduced PIFA of Figure 7(b) is contrasted to a conventional PIFA, whose radiator length is $34 \mathrm{~mm}$. The remaining dimensions are the same as those of the reduced PIFAs. Figures 10 and 11 present the comparison of the $S_{11}$ parameter and the radiation pattern, respectively, of the reduced and conventional PIFA.

Figure 10 shows a close convergence between the $S_{11}$ parameter of the conventional and the reduced PIFA. The simulated fractional bandwidth in both cases is about $4 \%$. However, the disadvantage of the reduced antenna is a lower port matching, going from $-18 \mathrm{~dB}$, for the conventional device, to -14 for the reduced PIFA. 


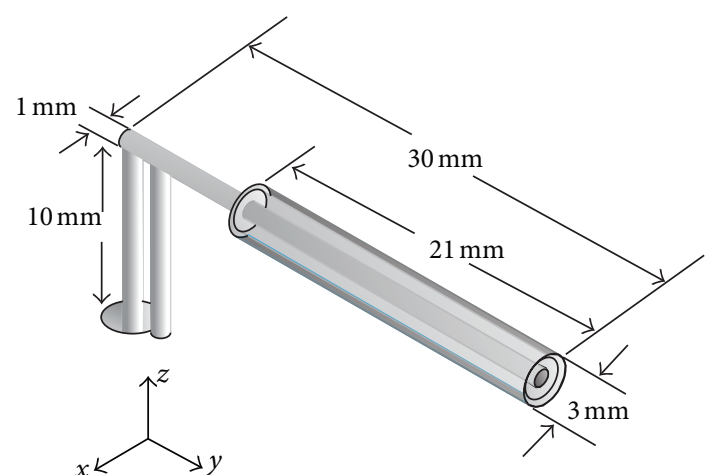

(a)

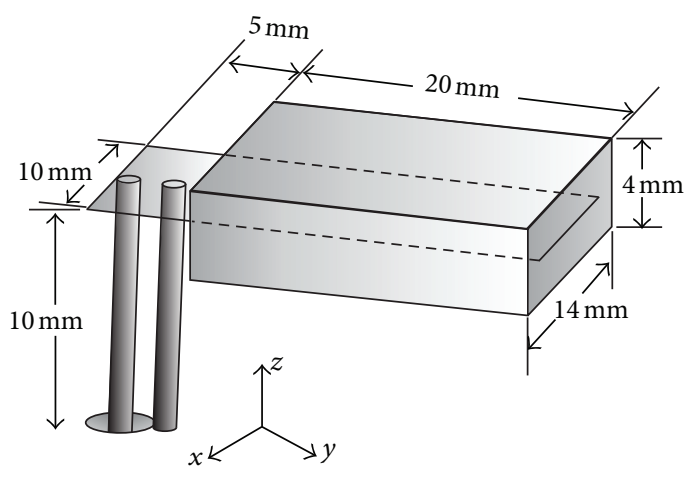

(b)

FIgURE 7: Proposed reduced antennas and (a) IFA, (b) PIFA.

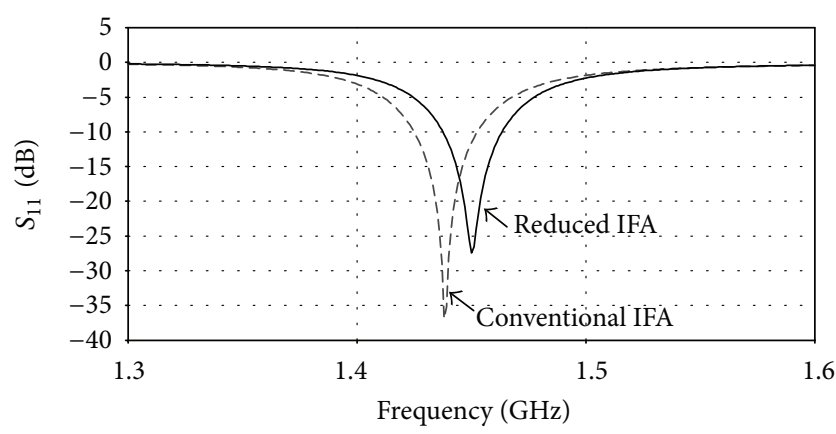

FIGURE 8: Comparison of simulated $S_{11}$ parameter of conventional and reduced IFA.

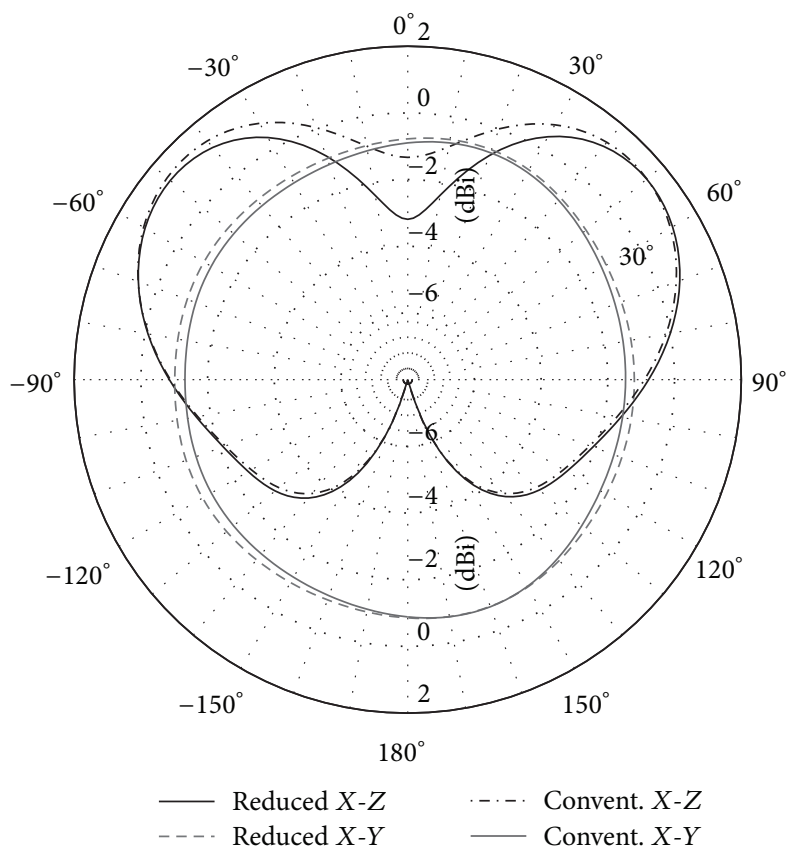

FIGURE 9: Simulated radiation pattern of reduced and conventional IFA.

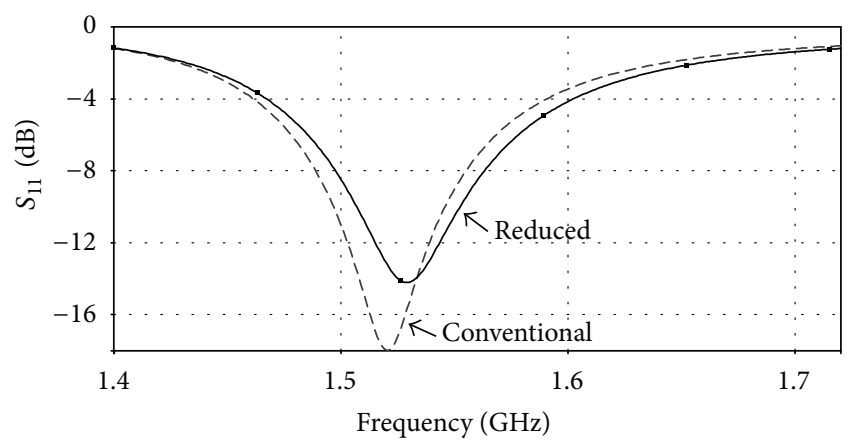

FIgURE 10: Comparison of the $S_{11}$ parameter of the reduced and conventional PIFA.

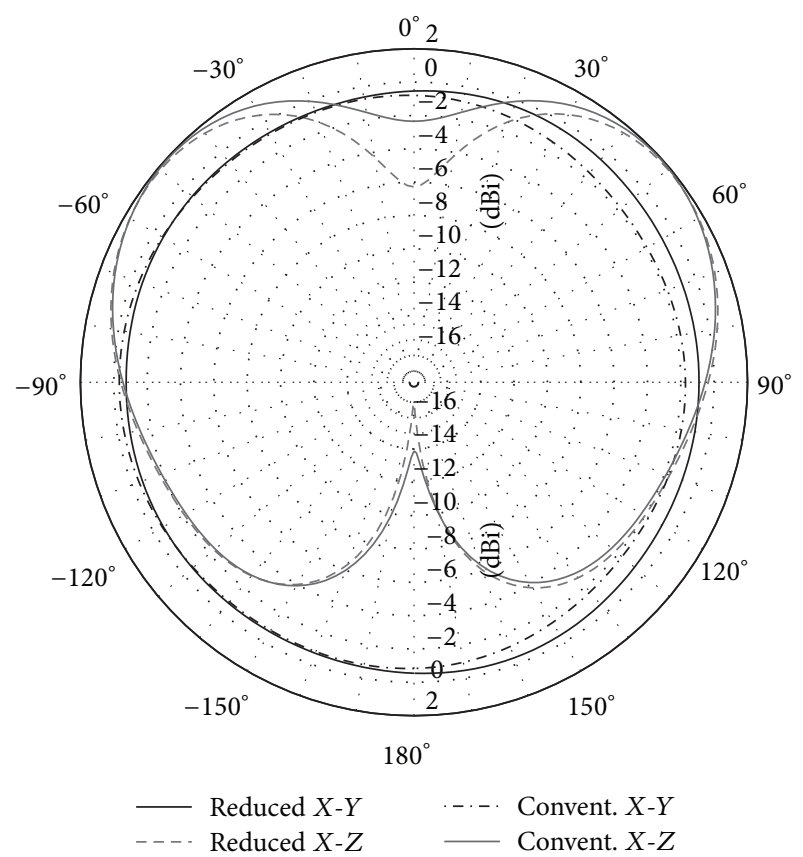

FIGURE 11: Comparison of radiation pattern of conventional and reduced PIFA. 


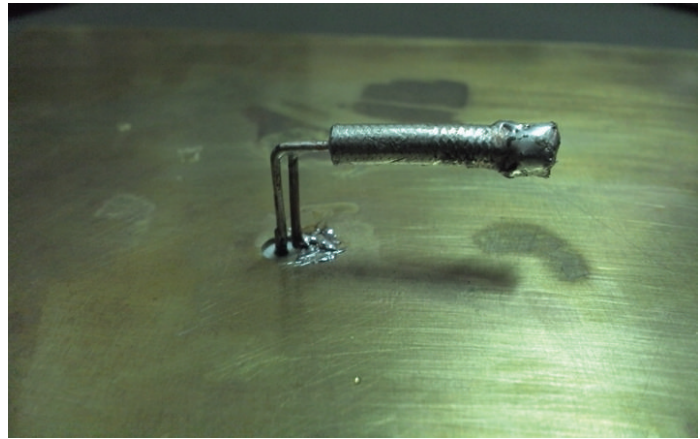

(a)

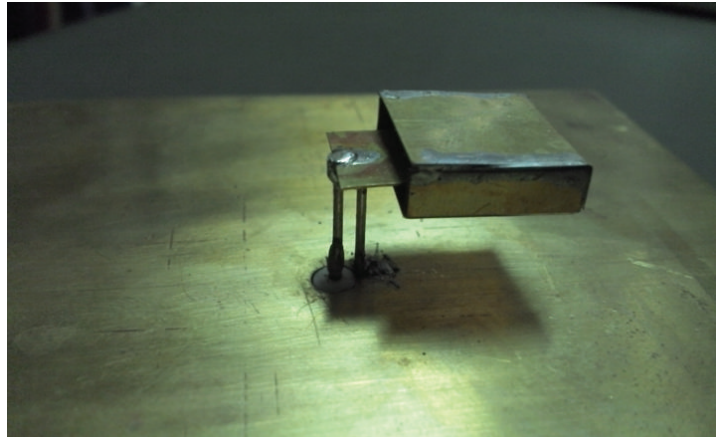

(b)

FIgURE 12: Prototypes of proposed antennas. (a) Reduced IFA, and (b) reduced PIFA.

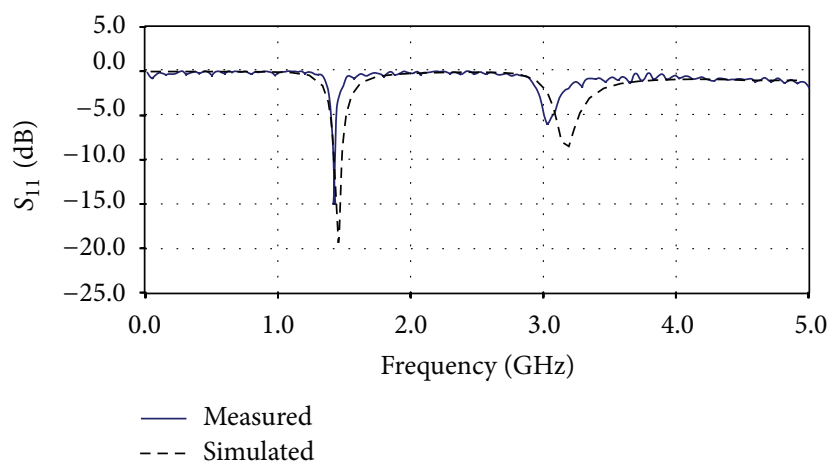

(a)

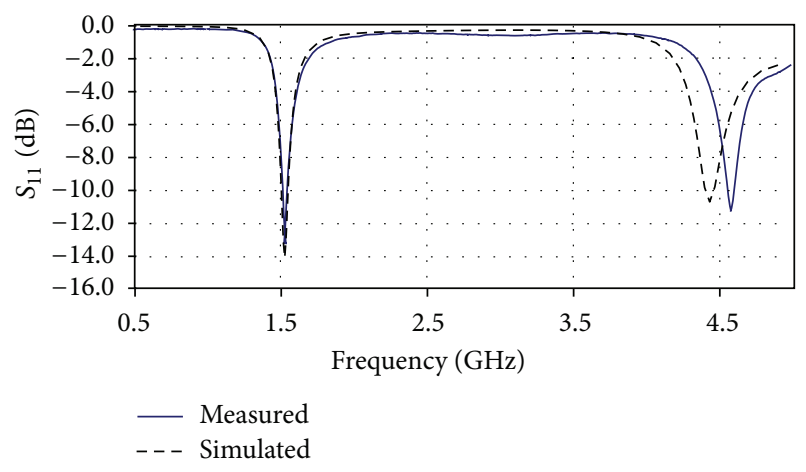

(b)

FIgURE 13: Comparison of simulated and measured $S_{11}$ parameter, (a) IFA and (b) PIFA.

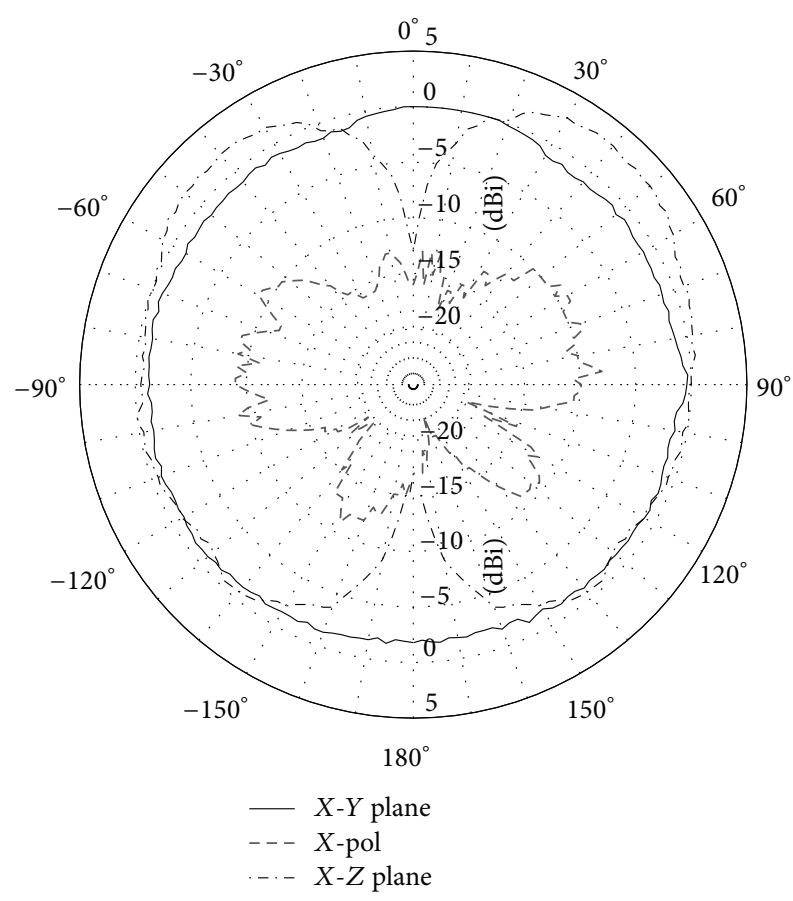

(a)

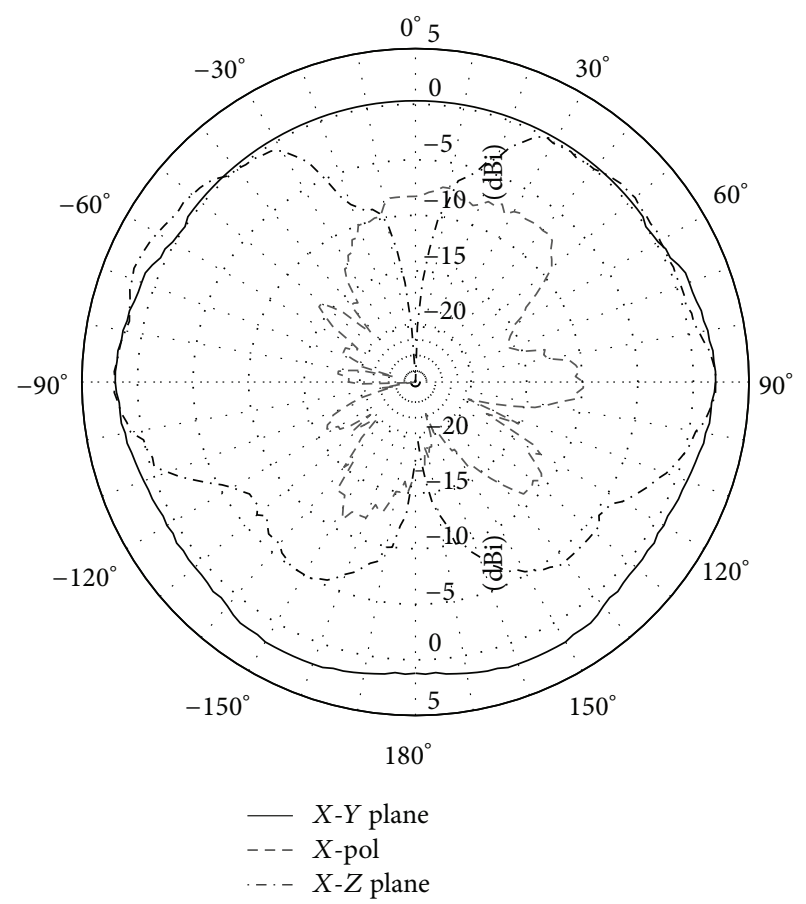

(b)

FIGURE 14: Measured radiation pattern of (a) reduced IFA and (b) reduced PIFA. 
The radiation pattern of the reduced PIFA is very similar to that of the conventional one, as deduced in Figure 11. Analyzing the results from Figures 10 and 11, it is concluded that both antennas perform alike.

However, also from Figure 11, there is a little difference between the gain magnitudes of the antennas. Even the omnidirectionality in the $X-Y$ plane is kept.

According to previous results and following dimensions given in Figure 7, the antennas were built and the prototypes are presented in Figure 12.

The measured and simulated $S_{11}$ parameter of the reduced IFA and PIFA prototypes is depicted in Figure 13.

A close convergence between the simulated and the measured results is got, and this is shown in Figure 13. The proposed technique performs adequately, achieving a size reduction around $30 \%$ for both cases, without significant changes in gain, radiation pattern, and bandwidth. On the other hand, the measured gain and radiation pattern are not considerably modified, as demonstrated in Figure 14.

Figure 14 shows the normalized measured gain pattern in the $X-Y$ plane and the $X-Z$ plane, as well as the crosspolarization level. As observed, both antennas have an omnidirectional radiation pattern and low cross-polarization level, which is around $20 \mathrm{~dB}$ less than the maximum gain. The average measured gain is close to $-2 \mathrm{~dB}$ in the $X-Y$ plane, which is comparable to the gain of conventional IFA and PIFA antennas. The fractional bandwidth is close to $4 \%$, which is bigger than that obtained by other methods [4]. As a result, the proposed technique allows reducing the size of the antennas around $30 \%$, but the radiation pattern, gain, bandwidth, and cross-polarization level are very similar to those parameters achieved by conventional IFA and PIFA structures.

\section{Conclusions}

Most size reduction techniques have the disadvantage of degrading the performance of antennas, by reducing either the radiation efficiency, the bandwidth, or the gain. In this work, a technique based on a stub loading is proposed to reduce the radiator length of an IFA and a PIFA. The technique loads the antenna with an inductive reactance, increasing the electrical length of the radiator, allowing obtaining a lower resonant frequency for a small size structure. The reduction factor is close to $30 \%$ and, theoretically, a bigger one could be reached if the stub is filled with a dielectric, increasing the slow-wave factor. This technique achieves a good trade-off between size reduction and performance degradation, which involves a very small reduction of the gain and the bandwidth and no modification of the radiation pattern shape.

\section{Acknowledgments}

This work was supported by Project CONACyT no. 127856 and Project SIP-IPN no. 20130564.

\section{References}

[1] J. A. Weiss, "Dispersion and field analysis of a microstrip meander line slow-wave structure," Microwave Symposium Digest, vol. 74, no. 1, pp. 165-167, 1974.

[2] A. K. Skrivervik, J.-F. Zürcher, O. Staub, and J. R. Mosig, "PCS antenna design: the challenge of miniaturization," IEEE Antennas and Propagation Magazine, vol. 43, no. 4, pp. 12-27, 2001.

[3] R. Li, G. DeJean, M. M. Tentzeris, and J. Laskar, "Development and analysis of a folded shorted-patch antenna with reduced size," IEEE Transactions on Antennas and Propagation, vol. 52, no. 2, pp. 555-562, 2004.

[4] A. Holub and M. Polívka, "A novel microstrip patch antenna miniaturization technique: meanderly folded shorted-patch antenna," in Proceedings of the 14th Conference on Microwave Techniques (COMITE '08), pp. 1-4, Prague, Czech Republic, April 2008.

[5] C. R. Rowell and R. D. Murch, "A capacitively loaded PIFA for compact mobile telephone handsets," IEEE Transactions on Antennas and Propagation, vol. 45, no. 5, pp. 837-842, 1997.

[6] C. Y. Chiu and C. H. Chan, "A miniaturized PIFA utilizing via-patch loading," in Proceedings of the Asia-Pacific Microwave Conference (APMC '05), vol. 1, pp. 1-3, December 2005.

[7] Y. Hwang, Y. P. Zhang, G. X. Zheng, and T. K. C. Lo, "Planar inverted F antenna loaded with high permittivity material," Electronics Letters, vol. 31, no. 20, pp. 1710-1712, 1995.

[8] Y. J. Wang, C. K. Lee, W. J. Koh, and Y. B. Gan, "Design of small and broad-band internal antennas for IMT-2000 mobile handsets," IEEE Transactions on Microwave Theory and Techniques, vol. 49, no. 8, pp. 1398-1403, 2001.

[9] K.-L. Wong and K.-P. Yang, "Modified planar inverted F antenna," Electronics Letters, vol. 34, no. 1, pp. 7-8, 1998.

[10] H. Jardon-Aguilar, J. A. Tirado-Mendez, R. Flores-Leal, and R. Linares-Miranda, "Reduced log-periodic dipole antenna using a cylindrical-hat cover," IET Microwaves, Antennas and Propagation, vol. 5, no. 14, pp. 1697-1702, 2011.

[11] J. A. Tirado-Mendez, H. Jardon-Aguilar, R. Flores-Leal, M. Reyes-Ayala, and F. Iturbide-Sanchez, "Inductively-loaded YagiUda antenna with cylindrical cover for size reduction at VHFUHF bands," IEEE Transactions on Antennas and Propagation, vol. 59, no. 2, pp. 357-362, 2011.

[12] J. A. Tirado-Mendez, H. Jardon-Aguilar, R. Linares-Miranda, H. Caltenco-Franca, R. Pena-Rivero, and R. Flores-Leal, "Combination of stub-loaded and DMS techniques for planar monopole size reduction," International Journal of $R F$ and Microwave Computer-Aided Engineering, vol. 22, no. 2, pp. 272279, 2012. 

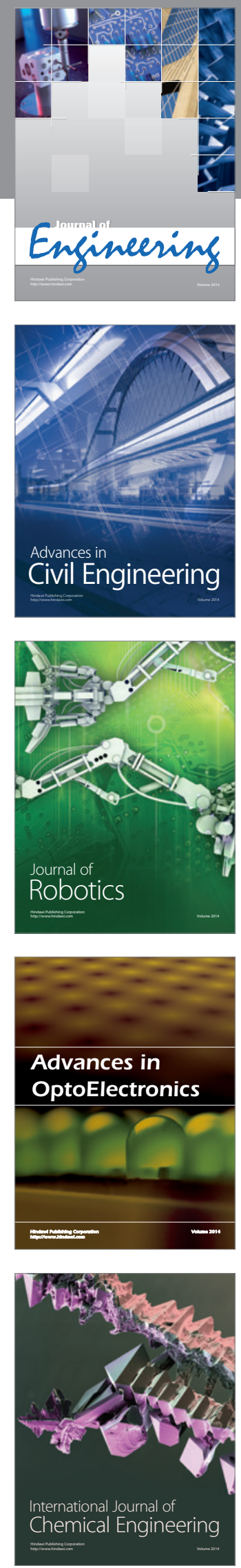

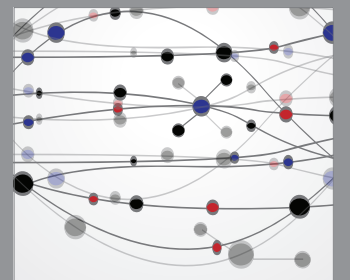

The Scientific World Journal
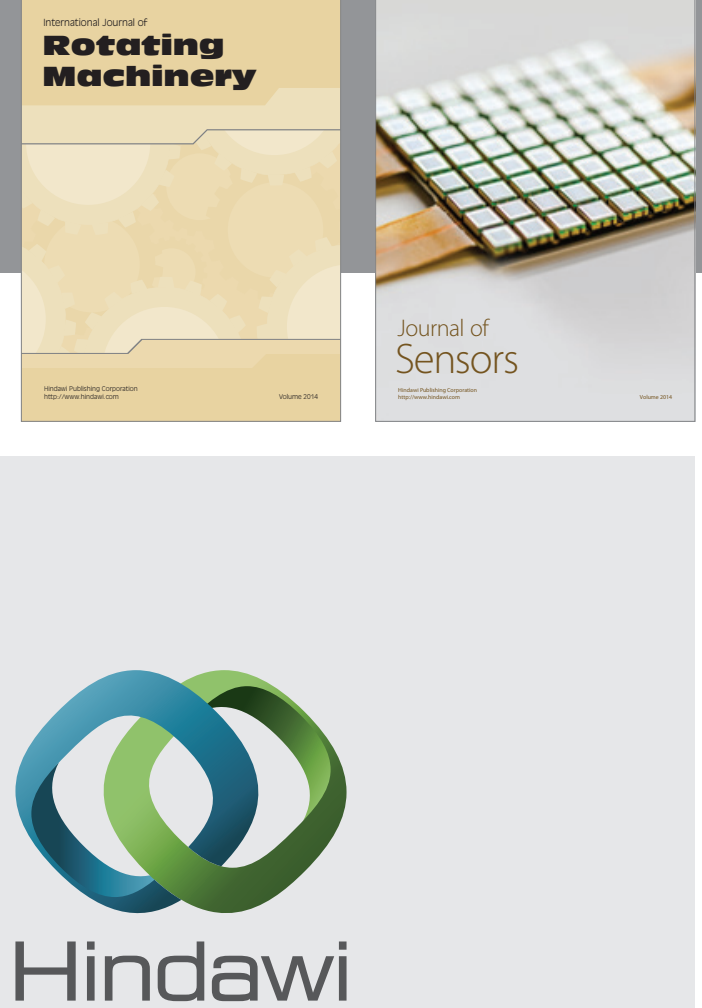

Submit your manuscripts at http://www.hindawi.com
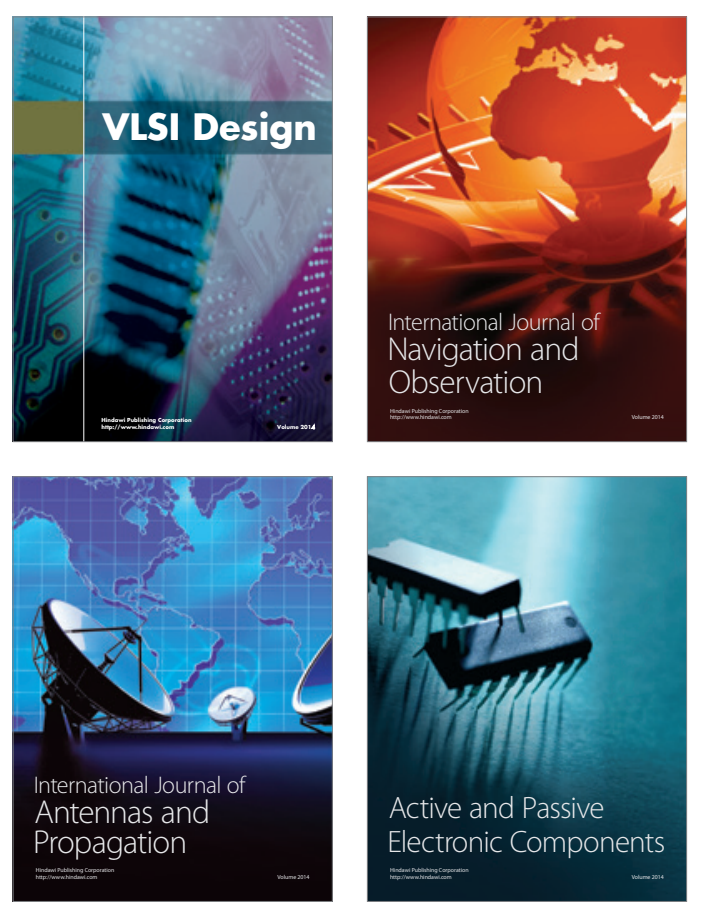
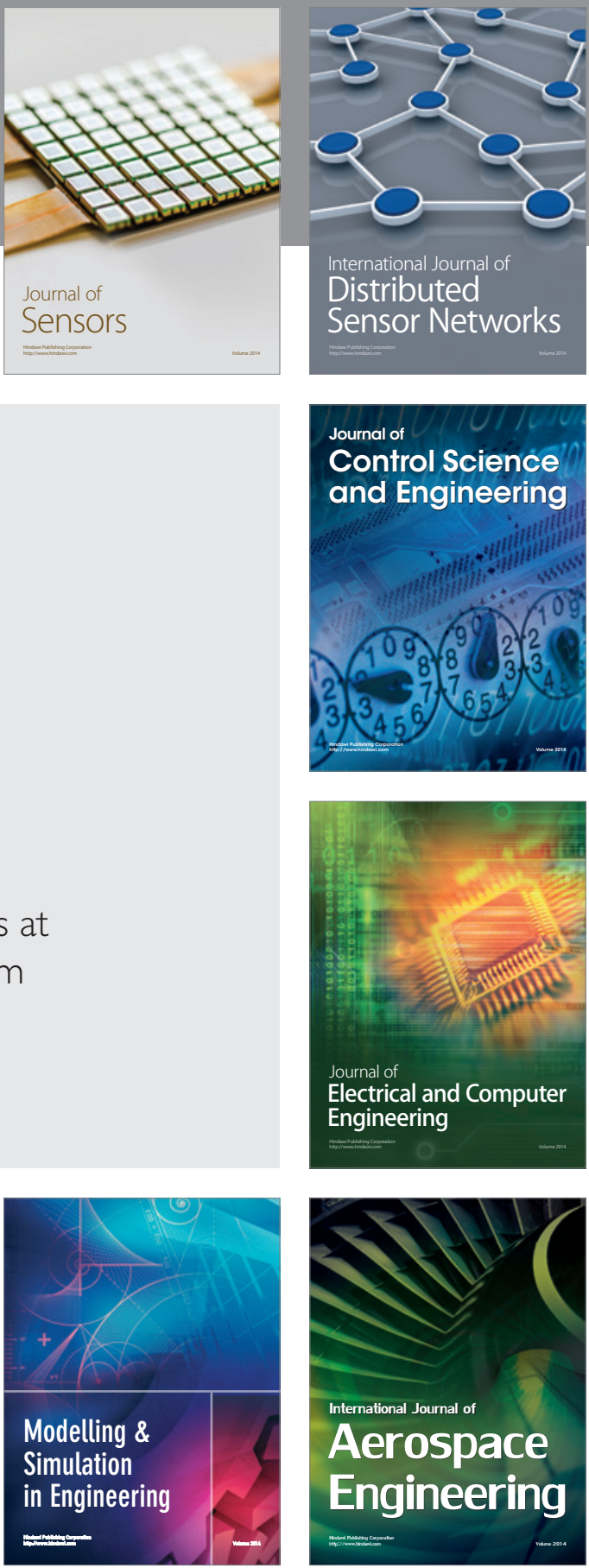

Journal of

Control Science

and Engineering
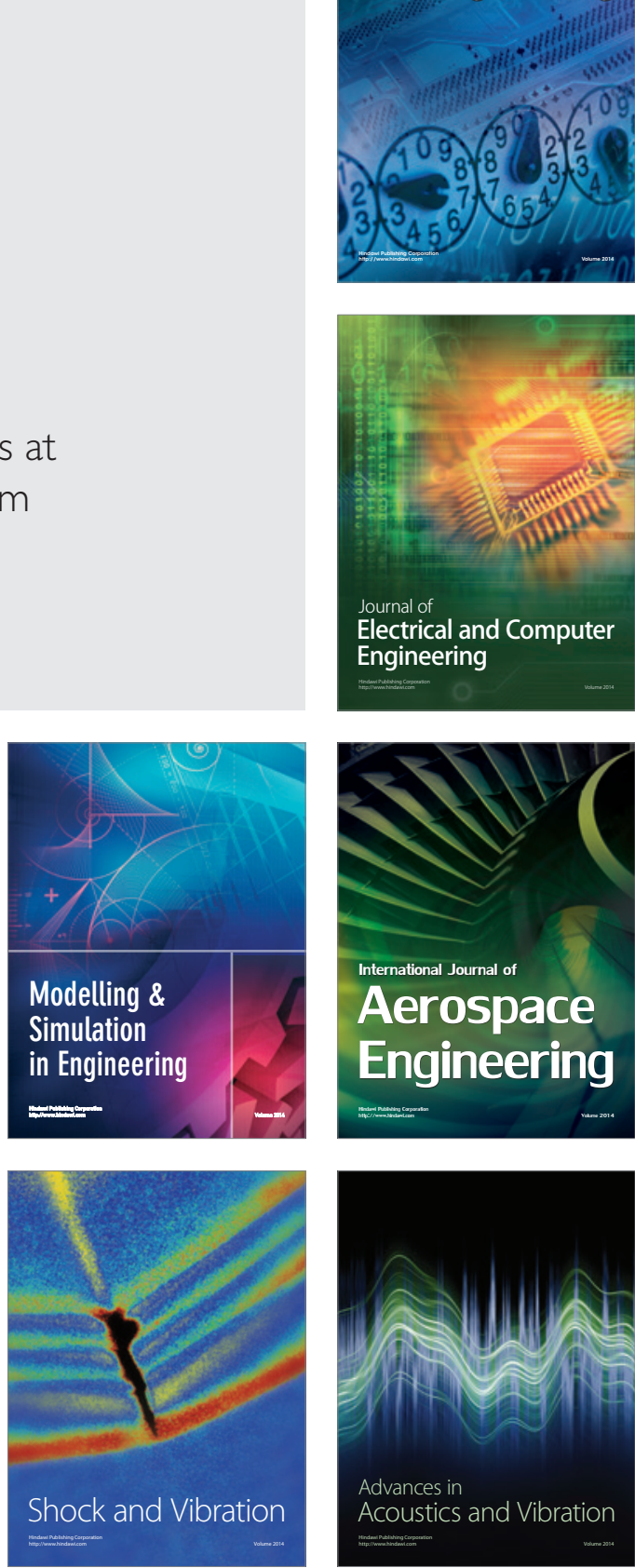